\title{
PhoneMe Poetry: Mapping Community in the Digital Age
}

\author{
Natalia Balyasnikova, Kedrick James
}

\begin{abstract}
АвSTRACт In this paper, we explore how an online-mediated place-based poetry tool enabled community self-representation. Located in a large Canadian city's urban core, the PhoneMe project brought academic researchers and community members together in a collaborative, educational, creative space. Community members created poems about specific places within their neighbourhood, dialled a designated phone number, and recorded the poem by leaving a voice message. On receiving the message, the academic team geotagged it on an interactive map, uploaded the poem's text, featured a Google Streetview image of the location, and shared the post via social media. Early results described a new vision for this remarkable physical space, and poems reached wider audiences via engagement with the poetic digital media. Plans have included include collaboration with urban libraries, the development of a new app, and have encouraged the use of engaged research-creation as a research method.
\end{abstract}

KeYWords community engagement, digital literacy, place-based literacy, mobile poetry, collaborative research

The University of British Columbia's Digital Literacy Centre (DLC) created the PhoneMe project as a scalable social media outlet for spoken poetry, mapping local community writing online, and showcasing it globally. Our overreaching goal was to build a poetry-based, digitally mediated map of one neighbourhood in Vancouver, B.C., and then sustain conversations about the place among diverse audiences. The process of voice recording a poem and sharing it as a specific pinned location and view/point on an interactive digital map addressed selfrepresentation issues in connection to place-based conceptions of community. Through an openly accessible web platform presenting the multiplicity of voices comprising a community, the project attends to a dialogical conception of community based on specialized (in contrast to spatialized) networks (Bessant, 2014). The physical and relational connections to place translate to the digital platform through the ambient acoustic qualities of the recorded messages heard by the users as they navigated the related geotagged location online.

This project emerged amidst a population remarkable for its resilience in the face of social challenges. The physical location of the project, the Downtown Eastside (DTES) of Vancouver, is a culturally diverse area dubbed by media outlets as the poorest postal code in North America (Hopper, 2014), a low-income ghetto (Geller, 2014), and a war zone (Mackie, 2020). While the media and government focus on alerting wider audiences to the area's unemployment (City of Vancouver, 2019), homelessness (Proctor, 2020), crime (Watson, 2019b), sex work, drug and alcohol addiction (Gee, 2018), and other social issues (Kurutcz, 2019), the DTES 
community has actively engaged in finding solutions to the challenges faced by its residents (Swanson, 2009). Attempts by the City of Vancouver to introduce projects aimed at DTES revitalization, particularly controversial residential developments, have sparked public debate (Mackie, Fumano, \& Lee-Young, 2017, McElroy, 2017), highlighting the polarization of public opinion on the future of a neighbourhood under the pressure of gentrification.

\section{Understanding 'community'}

Describing diverging conceptions of community within "the local public framework," Long (2008) writes:

Location indicates the politics of place. Without such attention to location, it would be tempting to say that local public life is primarily a rhetorical activity that circulates discourse-and leave it at that. Yet attending to location highlights the complex interplay here between situated activity... and discursive space. (p. 20)

In the context of university outreach, locations (e.g., community centres, libraries) play a sponsoring role as places where public aspects of community life are encouraged and translated into institutional discourses, practices, and pedagogies (Carrick, 2007; Long, 2008; Remley, 2012). Our goal was to provide an alternative forum and form of institutional sponsorship in which disruption of community-situated voices would not occur. To achieve this, particular attention needed to be paid to "different oral/literate mixes" (Street, 1993, p. 10), for much could be lost in translation of situated voices to public discourses.

As community-oriented language and literacy scholars, we developed this research-creation (Manning, 2016) project by overlaying two theoretical frameworks of community. The first rests on situated literacies (Barton et al., 2000; Lave \& Wenger, 1991; Street, 1993, 1995). Community literacy practices arise out of communicative needs and serve rhetorical purposes of self- and shared expression within a given, situated context. Moreover, a conceptualization of community must resist over-determination and over-generalization. Communities are never in stasis, never containable entities. They resist historicization and provide the raw materials for historical (and therefore political) culture to take place and all forms of societies to enact their social functions. As such, communities harbour the interplay of presence and absence, where the use of specialized, tacit information signals membership and marks the points of social order and interconnection (Lave \& Wenger, 1991). Concurrently, community serves purposes of com/memoration and archiving of events, people, and places in our lives (Cella, 2013; Haskins, 2007).

The second theoretical framework was that of virtual communities, a network-based relational model not constrained (or enhanced) by physical proximities but by access to, and literate with, digital technologies (Katz et al., 2004; Schau et al., 2012). The network conception of community, such as that represented by popular social media sites, both explodes and contracts the physical boundaries of community practices within a global framework accessible in spaces of physical privacy. This produces a disruptive effect on localized practices, 
as Bakardjieva (2003) writes: "Virtual togetherness has many variations, not all of which live up to the value-laden name of community" (p. 122). Now, in what amounts to an explosion in the means and ends of personal communication (to the group, of the group) through the digital scrambling of private and public worlds, the contemporary virtual community consumes discourse and extracts discursive resources by which it thrives.

This dual framework was useful to sustain a literacy practice that accesses virtual space and public dialogue on location, in a situated ideological context, using mobile phones. With the inclusion of digital practices, we imagined a specific hybrid community connected by the aesthetic practice of poetry and spoken arts with an understanding of the larger community in its dynamic state, housed in cyberspace but grounded in particular geo-located and physically determined circumstances, with fixed points of reference. With the PhoneMe project we attempted to create a ligature between these senses of community, drawing on the insider's viewpoint to create an interactive map experienced by outsiders, allowing the virtual community to experience geo-taggable places, architectures, and public objects in the DTES.

\section{The PhoneMe Process}

This article describes the first stage of the PhoneMe project and addresses the community-based aspect of its development. As such, we consider this paper as an introduction to the project, which, as of Fall 2020, is in its third iteration. As with many community-engaged projects, PhoneMe went through many co-design cycles and changed according to our community partners' needs. The first two months were spent engaging with UBC Learning Exchange and the affiliates of DTES Adult Literacy Roundtable, such as literacy outreach program coordinators for the Vancouver Carnegie Centre. In these consultations, we worked on the format and modes of delivery. As a result, PhoneMe took a flexible form with broad goals in mind but no rigid restrictions as to how the community members should engage. Our regular meetings took the form of joint "inquiry and praxis" (Peck et al., 1995) to engender a new form of community literacy that combines writing, verbal performance, and digital practices.

Partly due to the format of our outreach to the creative community of the DTES, the project started with three participants who had heard about the workshop through other literacy and arts-based organizations in the neighbourhood. Most of them had already been active in the creative life of $\mathrm{DTES}^{1}$, and some had attempted to have their poetry published and broadcasted ${ }^{2}$. Over four months, the project grew and brought together a group of ten people who met regularly to write, read, and celebrate the beauty of the spoken word and the power it has to transform the lives in the community. The new poets were at different stages of their creative journey, some only having shared their poetry in small creative groups or the streets. The small number of the first group of participants might be considered a limitation, for it did not include diverse DTES community members.

\footnotetext{
1 For example, Heart of the City Festival: http://www.heartofthecityfestival.com; Thursdays Writing Collective: http:// www.thursdayswritingcollective.ca

2 See for example, Downtown Eastside, a Creative Community - Interview with Gilles Cyrenne: https://thisvancouver.vpl. ca/islandora/object/islandora $\% 3 \mathrm{~A} 876$
} 
In the workshops we wrote together, using prompts to produce poems rapidly, some of which we intended to develop later and record as messages. After each round of prompts, we took a moment to hear the poems voluntarily read aloud, sharing our thoughts in the intimacy of spoken words. The poet could opt to reread the poem, this time performed with a phone and recorded on our answering service, making a PhoneMe submission. The workshops provided a physical, relational space to develop trust as a creative community first and practice, literally speaking, this new literacy practice.

Finally, we aimed to ensure that community practices developed in the neighbourhood were protected as they entered the global digital mediasphere. In each session, we would weave through discussions related to digital literacies such as privacy, intellectual property, surveillance, and so on; also, we took the opportunity to demonstrate creative uses of mobile phones, and to review functional aspects of the phonemeproject.com website, such as geotagging and using Google Street View. The digital literacies also included learning about voice editing, visual elicitation, self-publishing, and navigating online spaces.

PhoneMe workshops were designed to share poetic expression tools with DTES residents and encourage everyone to think expansively about their knowledge of the DTES. The digital platform was generated to assemble poetic representations of place and cultivate a sense of social responsibility by creating opportunities for participants to see their potential impact on the world-at-large. By the end of the first stage of the project, community members created over 80 poems and over 70 were recorded, on-site and off, and mapped online.

As a community-engaged project, we relied on open access free platforms to create a unique digital space for PhoneMe poets. We relied on a university-provided free online repository that hosted audio files of the phone messages left by the poets. These kept writers protected under the Freedom Of Information and Protection of Privacy Act (British Columbia, Ministry of Government Services, 1993). This repository was linked onto an interactive open access map hosted by the university. The website, which hosted poet introductions, project updates and most importantly the interactive map itself, was an open access blogging software connected to a Twitter feed.

\section{Impact}

We started PhoneMe with the conviction that community-based work needs to benefit the community members, activists, and community organizations. As mentioned in the introduction, DTES is a bustling creative community. This relatively small neighbourhood, which measures ten by 50 city blocks in size, harbours over 80 art galleries, 30 arts-based outreach centres, and a series of community magazines and newsletters. Moreover, there are regular poetry, storytelling, and music performances that take place throughout the neighbourhood. For the community residents, such variety presents a choice of mode and venue for self-determination, self-expression, and community participation. However, people who live in this neighbourhood do not always have creative access to big media platforms. Therefore, their vision for their community remains unrecognized or confined to the inner circle of the DTES residents. As a result, community voices are often left out from this 
neighbourhood's grand narrative as a space notorious for social challenges such as addictions, mental health issues, poverty, and crime. This is why featuring and sharing poems like Main \& Prior by one of PhoneMe poets, Gilles Cyrenne, is significant and valuable.

\section{Main \& Prior $^{3}$}

Once a neighbourhood, Hogan's alley, amazingly colourful history

Vera's Steak and Chicken House, open all night, 5-5

Way back in the 40's, 50's and early 60's, Jazz and cops and all night corruption

Informal clubs, bootlegs joints, rusty ducks

Louis Armstrong, Ella Fitzgerald, the Rat Pack, Frank Sinatra, Sarah Vaughan

Hung out at Vera's after hours whenever they came to town

Jimi Hendrix's Grandma worked there

Then a gang of philistine, pig-ignorant, white politicians

The cream of the corruption floating to the top decided a freeway was a better idea

Too many people having too much fun

BYOB clubs. Can't have that. Tear it all down. Build a freeway

Kill all that freedom and all night fun

Jazz and jitterbug

Good times gone

Way too wild for nice white guys

Way too wild for suits and bridge contractors

As a long-time resident of the DTES, Cyrenne grasped the historic development of the area, once a centre of art life in Vancouver, a wild space of "good times". Cyrenne also hints at the neighborhood's rapid gentrification, which, as argued by some (McElroy, 2019; Watson, 2019a), is one of the causes why the community's challenges have become more prominent.

Researchers from disciplines ranging from public health to geography investigate complexities of power, ideologies, and social ills in this neighbourhood. Whether these research projects are driven by academic curiosity or genuine concern for the future of the DTES, often research has been criticized for its 'parachute' approach and erasure of voices and concerns of this community ${ }^{4}$. The ethics of community engagement challenge this parachute in and out method, favouring giving back to the communities that contribute to research (Wesner et al., 2014) often done by sharing the findings with activist organizations, hosting public talks and events. We argue that this parachute approach legitimizes academic literacies as superior and thus devalues the knowledge and literacy forms pertinent to community members' daily needs. By opening the platform for the residents of DTES and presenting their work as it was written and performed, we aim to challenge the power relations inscribed through institutional and privileged — what Brian Street (1993, 1995) characterized as 'autonomous' - literacy practices.

3 Accessible at: https://story.mapme.com/phoneme/section/0f59a10c-298c-4d51-b409-c2777443aaff/details 4 See A Manifesto for Ethical Research in the Downtown Eastside for details: http://www.sfu.ca/content/dam/sfu/ sfuwoodwards/PDF/CommunityEngagement/Research101_Manifesto.pdf 
The DTES interactive map features different poetry styles, addresses a variety of issues, criticizes existing policies, and showcases the linguistic and cultural diversity of the neighbourhood. Immediate benefits for community participants included the creative development of poetic multimodal literacy practices and drawing public attention to community issues, celebrations or mourning of essential moments, places, and persons within the community.

Dialoguing through the digital platform has become a way for PhoneMe poets to open a space for communicating across boundaries. Having a platform to dialogue on issues that matter, in a concise verbal mode of address, made the exchange memorable. To illustrate, one issue that participants dealt with was the rapid changes in the neighbourhood. These changes included a rezoning plan, which opened the neighbourhood to new residential and commercial development. While some participants of the workshop celebrated these changes, they were opposed by others. In this context, the prompt was "something you would build within 100 steps". Coming from different walks of life, we had a thought-provoking discussion around what developments are needed in the DTES. Some insisted that the development pushed the residents out of the neighbourhood; others took a more contemplative stance towards the change. As the poems were uploaded onto our interactive map the poets created an online dialogue, a commentary on the state of their neighbourhood. Consider the following two poems that were written in response to the prompt written by Graham Cunningham and Gilles Cyrenne.

\section{Treehouse ${ }^{5}$ \\ Graham Cunningham}

I want to build a treehouse in the tree outside Starbucks

Purely for the significance of having a place in public where I could sit and meditate.

\section{What I would build ${ }^{6}$ \\ Gilles Cyrenne}

I would build a geodesic shaped camper on the flat deck back of a small four wheel drive truck so that I could have a place to live that keeps me rolling ahead of the confining bourgeois bohemian boo boo gentrifiers.

Plus it would be nice to get out of town and go camping once in awhile.

On a broader scale, the project amplified community voices through our interactive online platform. By speaking directly to issues of concern to the community's, PhoneMe poets claimed an agentive role in their neighbourhood's future. This increased community's capacity to respond meaningfully and compassionately to the negative representations prominent in the media, government reporting, and general public discourse. Poets geotagged spaces in the DTES that provoked a memory, a reflection, or an emotion. Such is an example of Granville

5 Accessible at: https://story.mapme.com/phoneme/section/9266cb93-913f-46aa-ac04-f40196ad6c14/details

6 Accessible at: https://story.mapme.com/phoneme/section/bd5f9ca1-648e-4e71-b169-9524b190702b/details 
Street by Gilles Cyrenne, a celebration of life, beauty, youth, and compassion harboured on Granville - one of Vancouver's main streets. In contrast, Mila Klimova's Listening Post is a eulogy to community member Lorraine, who provided emotional and spiritual support to the community since 2001. Both of these poems, so different in tone, depict DTES as a multifaceted involved community and open the general publics' eyes and hearts to this multilayered complexity.

\author{
Granville Street ${ }^{7}$ \\ Gilles Cyrenne \\ Sunny February day \\ Mountains to the North \\ Water, ocean \\ Hustle and Bustle \\ Bustle and Hustle \\ Full with beautiful young people \\ Also wandering, me and a few other seniors \\ Vancouver, I love you \\ On the corner, Blues guy busking \\ Couple of hot-dog stands \\ A lovely young woman with a sign, "Free \\ Hugs" \\ I enjoy one \\ Vancouver, will you marry me?
}

\author{
Listening Post ${ }^{8}$ \\ Mila Klimova \\ At the Listening Post \\ Everybody liked the most \\ Our sweet Lorraine \\ Night and day \\ She chased the pain away \\ Near Hastings and Main \\ Her attentive ear \\ Was everyone's dear \\ Companion. \\ Listening post's champion of compassion, \\ Soldier of the invisible front \\ For a better tomorrow, is gone. \\ Today we are in sorrow - \\ There is no sweet Lorraine \\ Near Hastings and Main.
}

Enhancing dialogue and knowledge exchange is a fundamental goal of community literacy projects (Peck et al., 1995). Being present in the community physically and dialoguing with the community digitally became a reflexive practice for the poets who joined our workshops. In one of the workshops, Graham Cunningham shared a poem about Simon Fraser University's Downtown Vancouver campus in Harbour Centre. By the nature of being located near the Downtown Eastside, Harbour Centre comprises open public facilities. But for many residents of the DTES, spaces such as these are a symbol of academic ivory tower power, casting a shadow on their community. However, when creative practices take a legitimate place near institutional literacy forms, the power balance shifts, and knowledge exchange begins.

7 Accessible at: https://story.mapme.com/phoneme/section/ed4d72f1-dc52-46bf-a0df-01eab90fc0a6/detail

8 Accessible at: https://story.mapme.com/phoneme/section/9fc0dfe5-50c5-44df-bdb4-076cb7b861c2/details 


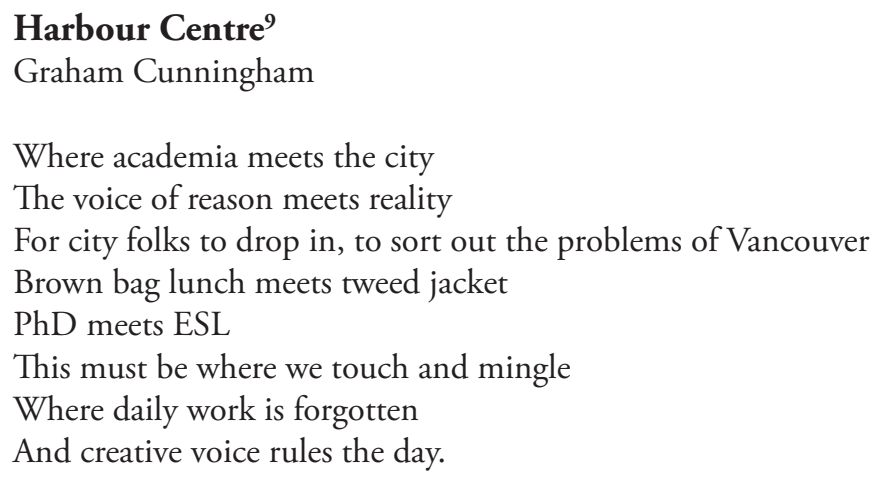

This poem calls for personal reflection for both sides of the community and the creation of a new community that is reflective and open to everyone.

\section{Final Words}

Today, humans have access to a multitude of modes of digital communication: words, videos, images, colours, sounds, textures. Aesthetics have a practical and functional role in the distribution of human relations and networks. Once the dominant cultural frames of aestheticism are removed in a pejorative and prejudicial sense, multiple literacies become apparent. Each of these practices requires community, regardless of headcount, to be practiced. This is why, when talking about community, we should consider a deeply felt human desire to carve out a space of belonging, to communicate our presence, to map our emergent values. The PhoneMe project blurred boundaries between physical connections and institutional ties by facilitating the poets, UBC researchers, and workshop facilitators to create and embody different roles within a project.

PhoneMe also created a fuzzy middle ground between the social expansion of the individual and the legitimate contract of cultural powers that govern individuals, and this gave us insight into how a community, born out of poetic social practice and resultant discourse, makes possible the passage from one pole of this continuum to the other. In this reconstituting practice of individualization and distinction, celebration and preservation, collaboration and collective effort, grand narratives of contemporary society lose their special force of description. By presenting and legitimizing their view of the DTES, PhoneMe poets revitalized a polyglot, hybridized community present both on the physical streets and the digital ones.

We recognize that this project represents a pilot in the current research-creation environment within the DTES, and our limitations include a small number of poet-collaborators, and a small number of collaborating institutions. While we continue the project (next steps described below), we are attuned to the processes we are using, and feedback on how to improve processes for wider participation.

9 Accessible at: https://story.mapme.com/phoneme/section/ea6f806a-3847-4f8b-a146-fa1b6e90a104/details

Engaged Scholar Journal: Community-Engaged Research, Teaching and Learning 
Now that we have finalized the first stage of the PhoneMe project, as described in this article, the research team has moved on to the second iteration of workshops through the Vancouver Public Library, n'́c'a?mat ct Centre at the Strathcona Branch. We continue exploring possibilities of facilitating digital value mapping through poetry in other contexts. We have engaged with secondary schools in British Columbia and pre-service teachers in British Columbia and Ontario. The Digital Literacy Centre team is currently working on an app that will further facilitate digital poetry creation.

\section{About the Authors}

Natalia Balyasnikova (corresponding author) is an Assistant Professor at York University, Faculty of Education. Her research explores older immigrants' educational engagement in community-based settings. Using narrative ethnographic methods, she merges traditional ethnographic data generation with arts-based activities, such as poetry, drama, and storytelling. Email: natbal@yorku.ca

Kedrick James is the Director of the Digital Literacy Centre in the Department of Language and Literacy Education at the University of British Columbia. His research interests span ecological and digital poetics, automation of literacy, and network theory. Recent projects include PhoneMe, geotagged social media for poets, Glitch Pedagogy, using disruptive strategies to reveal algorithmic processes, and Digital DIY exploring computational thinking through haptic play. Recent publications include Poetic Inquiry: Enchantment of Place (2017), a coedited volume published by Vernon Press. Email: kedrick.james@ubc.ca

\section{References}

Bakardjieva, M. (2003). Virtual togetherness: an everyday-life perspective. Media, Culture \& Society, 25(3), 291-313. https://doi.org.10.1177/0163443703025003001

Barton, D., Hamilton, M., \& Ivanič, R. (Eds.). (2000). Situated Literacies: Reading and Writing in Context. Psychology Press.

Bessant, K. C. (2014). The relational genesis of community: Self-other dialogue. Journal of Community \& Applied Social Psychology, 24(6), 467-478. https://doi.org.10.1002/casp.2185

British Columbia. Ministry of Government Services. (1993). Freedom of information and protection of privacy, Province of British Columbia. Province of British Columbia. 
Carrick, T. H. (2007). Bootlegging Literacy Sponsorship, Brewing up Institutional Change. Community Literacy Journal, 2(1), 25-39.

Cella, L. (2013). Introduction: Taking stock of our past and assessing the future of community writing work. In L. Cella, \& J. Restaino, (Eds.). Unsustainable: Re-imagining Community Literacy, Public Writing, Service-learning, and the University (pp. 1-14). Lexington.

City of Vancouver. (2019). Jobs and economy snapshot for the Downtown Eastside. https://vancouver.ca/ files/cov/jobs-and-economy-snapshot-dtes.pdf

Gee, M. (2018, November, 9). What I saw in a day on the Downtown Eastside shocked me. The Globe and Mail. https://www.theglobeandmail.com/canada/article-what-i-saw-in-a-day-onthe-downtown-eastside-shocked-me/

Geller, M. (2014, March 3). Downtown Eastside Plan: Low-income ghetto needs to be normalized. Huffington Post. https://www.huffingtonpost.ca/michael-geller/downtown-eastside-planvancouver_b_4892929.html

Haskins, E. (2007). Between archive and participation: Public memory in a digital age. Rhetoric Society Quarterly, 37(4), 401-422. https://doi.org.10.1080/02773940601086794

Hopper, T. (2014, November 15). Vancouver's 'gulag': Canada's poorest neighbourhood refuses to get better despite $\$ 1 \mathrm{M}$ a day in social spending. National Post. https://nationalpost.com/news/ vancouvers-gulag-canadas-poorest-neighbourhood-refuses-to-get-better-despite-1 m-a-day-insocial-spending

Katz, J. E., Rice, R. E., Acord, S., Dasgupta, K., \& David, K. (2004). Personal mediated communication and the concept of community in theory and practice. In P. Kalbfleisch (Ed.), Communication and Community, 28 (pp. 315-371). Erlbaum.

Kurutcz, J. (2019, August 19). How do you explain Vancouver's Downtown Eastside to tourists? It's complicated...Vancouver Courier. https://www.vancourier.com/news/how-do-you-explainvancouver-s-downtown-eastside-to-tourists-it-s-complicated-1.23920263

Lave, J. \& Wenger, E. (1991). Situated Learning: Legitimate Peripheral Participation. Cambridge.

Long, E. (2008). Community Literacy and the Rhetoric of Local Publics. Parlor Press.

Mackie, J. (2020, May 2020). John Mackie: The Downtown Eastside is a war zone disaster Stop ghettoizing it. Vancouver Sun. https://vancouversun.com/opinion/john-mackie-thedowntown-eastside-is-a-war-zone-disaster-stop-ghettoizing-it

Mackie, J., Fumano, D., \& Lee-Young, J. (2017, November 08). Developers shocked city turned down Chinatown development. Vancouver Sun. http://vancouversun.com/news/local-news/ developers-shocked-city-turned-down-chinatown-development

Manning, E. (2016). Ten propositions for research-creation. In Collaboration in Performance Practice (pp. 133-141). Palgrave Macmillan.

McElroy, J. (2019, August 21). The biggest change in the Downtown Eastside isn't the crime or homelessness. It's the geography. $C B C$. https://www.cbc.ca/news/canada/british-columbia/ dtes-vancouver-statistics-anecdotes-1.5253897

Peck, W. C., Flower, L., \& Higgins, L. (1995). Community literacy. College Composition and Communication, 46( 2), 199-222. https://doi.org.10.2307/358428

Proctor, J. (2020, April 3). Will COVID-19 force change in Vancouver's troubled Downtown Eastside neighbourhood? $C B C$. https://www.cbc.ca/news/canada/british-columbia/ downtown-eastside-covid-crisis-1.5518242

Engaged Scholar Journal: Community-Engaged Research, Teaching and Learning 
Remley, D. (2012). Re-considering the Range of Reciprocity in Community-Based Research and Service Learning: You Don't Have to be an Activist to Give Back. Community Literacy Journal, 6(2), 115-132. https://doi.org.10.1353/clj.2012.0025

Schau, V., Kirchner, K., Stolcis, C., Erfurth, C., Eichler, G., \& Rossak, W. R. (2012). Mobile communities - current status and challenges. In A. Lazakidou (Ed.) Virtual Communities, Social Networks and Collaboration (pp. 221-237). Springer.

Street, B. (1993). Introduction: The new literacy studies in B. Street (Ed.) Cross-cultural Approaches to Literacy. Cambridge.

Street, B. (1995). Social literacies: Critical approaches to literacy in development, Ethnography and Education. Longman.

Swanson, J. (2009, October 24). Residents suggest solutions to Downtown Eastside problems. Vancouver Sun. https://vancouversun.com/news/community-blogs/residents-suggestsolutions-to-downtown-eastside-problems

Watson, B. (2019, August 17)a. How did we get here? Failed public policy and Vancouver's Downtown Eastside. CBC. https://www.cbc.ca/news/canada/british-columbia/dtes-worsethan-ever-early-edition-1.5247314

Watson, B. (2019, September 3)b. Vancouver police say violent crime on the rise on the Downtown Eastside. $C B C$. https://www.cbc.ca/news/canada/british-columbia/violent-crime-increasingdtes-1.5273762

Wesner, A. B., Pyatt, J., \& Corbin, C. N. E. (2014). The practical realities of giving back. Journal of Research Practice, 10(2), M6. 